\title{
Bolts Gauge Effect on the Face Bending Behaviour of Concrete-Filled Hollow Section for Hollo-Bolted Connections
}

\author{
Ahmed Elamin ${ }^{1, a^{*}}$, Walid Tizani ${ }^{2, b}$ and Mohammed Mahmood ${ }^{2,3, c}$ \\ ${ }^{1}$ Department of Civil Engineering, The University of Nottingham, China Campus, China \\ ${ }^{2}$ Department of Civil Engineering, The University of Nottingham, United Kingdom \\ ${ }^{3}$ Department of Civil engineering, University of Diyala, Iraq \\ aahmed.elamin@nottingham.edu.cn, bwalid.tizani@nottingham.ac.uk, \\ cevxmsma@nottingham.ac.uk
}

Keywords: Hollow Sections, Blind Bolts, Bolt Gauge, Face Bending.

\begin{abstract}
This paper investigates the effect of bolt gauge on the face bending behaviour of concrete-filled Square Hollow Sections (SHS) in Hollo-Bolted connections. A set of full-scale experiments were undertaken to examine the effects of varying the bolt gauge on the SHS face bending behaviour while controlling all other parameters. Typical experiment involved one row of two bolts pulled out of concrete-filled SHS. A special dummy bolts were manufactured to the exact size and geometry of open Hollo-Bolts, and were used in the experiments to remove the influence of any deformation associated with the real Hollo-Bolts, and isolate the face bending behaviour. Noncontact video-based equipment was used to record the SHS face deformation. This deformation is recorded as force-displacement relationship which is commonly used to represent the structural behaviour of similar components, and typically defined by initial stiffness, yield force and post yield stiffness. Across the range considered in this investigation, it was found that varying the bolt gauge to SHS width ratio have a significant effect on the concrete-filled SHS face in bending component. Both the initial stiffness and the yield force of the component were found to increase with the increase of the bolt gauge. The Post-Yield stiffness was not affected by the change in bolt gauge.
\end{abstract}

\section{Introduction}

The structural performance of Structural Hollow Sections is superior when compared to the open sections. Nevertheless, the practical use of these sections is limited due to complexities involved in their connections. The lack of access to the interior of these sections makes it almost impossible to use standard bolted connections.

Special fasteners are used to alleviate these complexities by allowing for bolted welded connections to hollow sections; they are called Blind Bolts. Lindapter's Hollo-Bolt is one of these fasteners currently available in the market in two types as shown in Fig. 1.

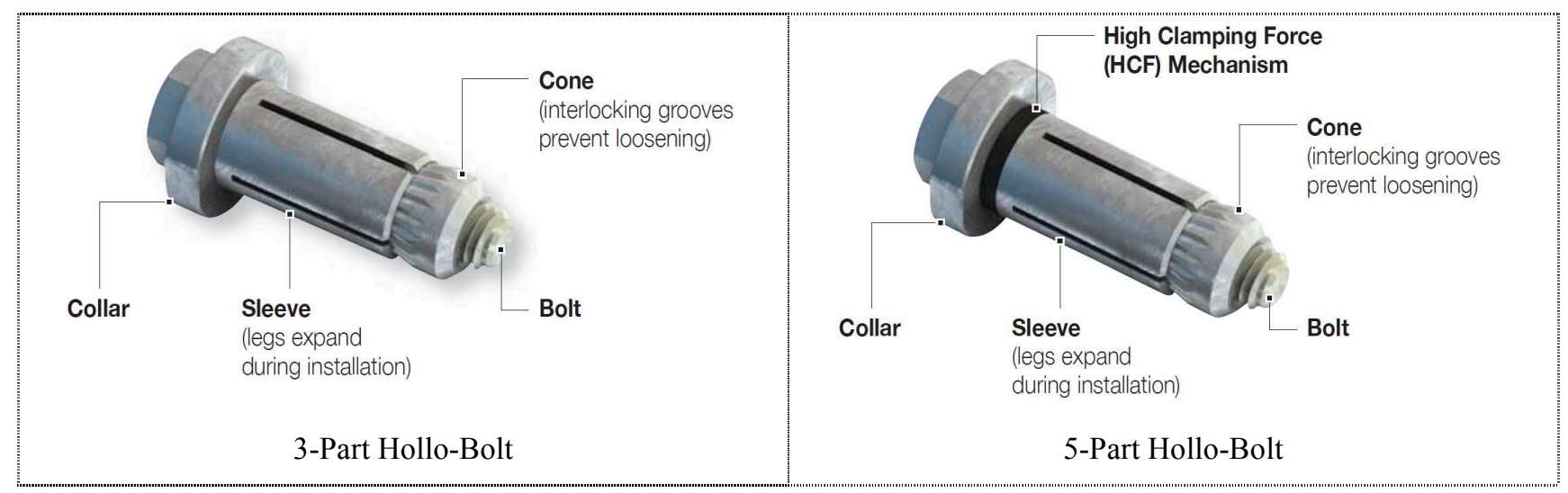

Fig. 1: Lindapter Hollo-Bolt [1] 
The established use of Lindapter Hollo-Bolts is currently restricted to transferring tensile forces and vertical shear only - safe working loads can be found in manufacturer brochures [1]. Filling Square Hollow Sections (SHS) with concrete was found to improve the performance of Hollo-Bolted connections in resisting moments [2], but there is currently no guidance available on how to model the behaviour of such connections.

To model connections in accordance to the Eurocode 3, each connection is split into basic components so that each component is evaluated separately. Force-displacement curves are commonly used to define components' behaviour. The behaviour of all components is then combined to model the overall behaviour of the connection [3]. This method is widely known as the component method and is used in numerous investigations such as [4 - 9].

For Hollo-Bolted moment resisting connections, the behaviour of the Hollo-Bolt in tension component and the bending of the connected side of concrete-filled SHS component - known as SHS face bending - are not currently available. Many factors can affect the behaviour of these components such as concrete-infill grade and slenderness ratio of SHS face [10]. Moreover, as Hollo-bolted connections to Hollow Section involve multiple rows of bolts, the distance between the bolts in each row - known as bolt gauge - could affect to the face bending behaviour. Yet it's effect in not yet explored. This paper experimentally investigates the effect of varying the bolt gauge on the face bending behaviour of concrete-filled SHS. It focused in Hollo-Bolted connections where one row of Hollo-Bolts - consists of two Hollo-Bolts - is subjected to tension. The experiments are described in the next section. This is followed by the results and discussions section. Concluding remarks are included in the final section of the paper.

\section{Experimental Details}

The experiments conducted in this investigation are designed to evaluate the effect of varying the bolt gauge on the face bending behaviour of concrete-filled SHS. It involved pulling two bolts out of concrete-filled SHS while recording the SHS face bending as force-displacement relation.

Typical SHS sample is $600 \mathrm{~mm}$ in length cut from SHS $200 \times 200 \times 8$, has one row of Hollo-Bolts, filled with concrete and restrained at its end. This length of the SHS samples was decided to allow the SHS face to bend without restrictions. Typical SHS sample layout is shown in Fig. 2.

Especially manufactured dummy bolts were used in this experimental programme to isolate any deformation or energy dissipation associated to the use of standard Hollo-Bolts. Such deformations previously encountered in previous experimental programme [11]. The dummy bolts were manufactured from EN24 steel to the dimensions of opened Hollo-Bolts HB-16 (available to download from [1]). One of the dummy bolts is shown in Fig. 3.

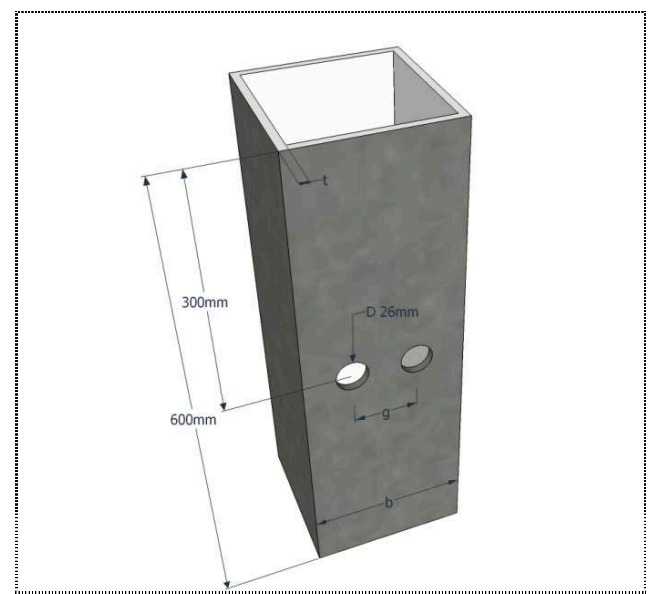

Fig. 2: Typical SHS sample layout

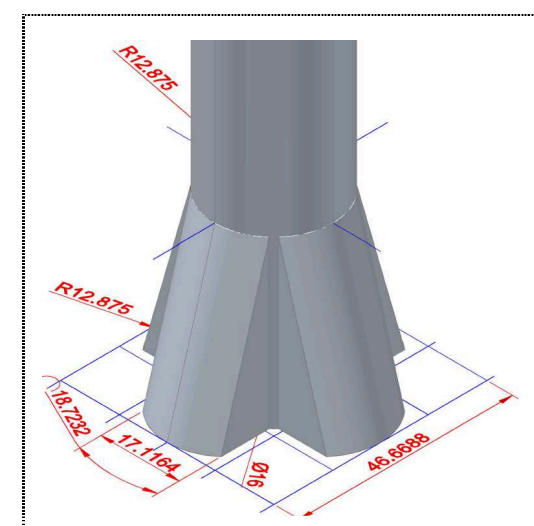

(a) 3D Model of dummy bolt

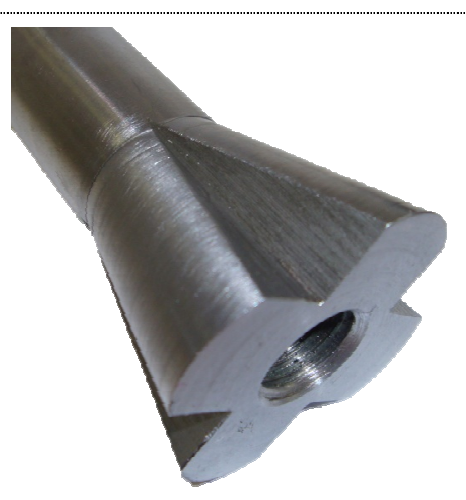

(b) Manufactured dummy bolt

Fig. 3: Dummy Bolt 
The SHS samples were filled with concrete which is designed to produce $40 \mathrm{~N} / \mathrm{mm}^{2}$ cube compressive strength at the day of testing. The samples were cut from the same SHS tube to eliminate any discrepancy associated with the material properties of the SHS.

Three different values for the bolt gauge were tested: 60, $80.100 \mathrm{~mm}$. Sample details are shown in Table 1. Two identical repetitions at least of these samples were tested.

Table 1: Test Matrix

\begin{tabular}{|c|c|c|c|c|c|}
\hline \multirow[b]{2}{*}{ n. } & \multirow{2}{*}{ Hollow Section } & Width (b) & Thickness (t) & Concrete Grade & Bolt Gauge (g) \\
\hline & & [mm] & {$[\mathrm{mm}]$} & {$\left[\mathrm{N} / \mathrm{mm}^{2}\right]$} & {$[\mathrm{mm}]$} \\
\hline 1 & SHS 200×200x8 & 200 & 8 & 40 & 60 \\
\hline 2 & SHS $200 \times 200 \times 8$ & 200 & 8 & 40 & 80 \\
\hline 3 & SHS 200x200x8 & 200 & 8 & 40 & 100 \\
\hline
\end{tabular}

The bolts were pulled-out from the SHS using an electro-hydraulic Servocon ${ }^{\circledR}$ actuator with a capacity of $450 \mathrm{kN}$. Non-contact video-based equipment was used to record the face bending called Imetrim ${ }^{\circledR}$ Video Gauge. The movement of magnetic targets attached to the SHS face was recorded using the Video Gauge to represent SHS face displacement.

The applied force was logged using load cell attached to the actuator and fed into the Video Gauge system to simultaneously produce force-displacement curve of each experiment. More details of this experimental programme can be found in [10].

\section{Results and Discussions}

The aim of the experimental programme is to control all parameters and only vary the bolt gauge to evaluate its effect on the SHS face bending. However, slight variation was observed in concreteinfill compressive strengths when concrete cubes samples where tested on the day of testing (shown in Table 2). This is due to the fact that curing concrete from different batches to exact compressive strength is not possible even though the same mix-design is used. Therefore, the force-displacement curves of all tests were normalised using the equation:

$$
\text { Force }_{\text {normalized }}=\text { Force }_{\text {actual }} \times \mathrm{f}_{\text {cu-target }} / \mathrm{f}_{\text {cu-actual }} \text {. }
$$

where Force $_{\text {actual }}$ is the force recorded from actuator, $f_{\text {cu-target }}$ is the targeted concrete cube compressive strength (equal to $40 \mathrm{~N} / \mathrm{mm}^{2}$ ), and $\mathrm{f}_{\text {cu-actual }}$ is the cube compressive strength of the concrete-infill on the day of testing (averaged). The Normalised force-displacement curves are shown in Fig. 4: a, b and c.

In general, the outlines of the force-displacement curves followed the same pattern in all tests. The force initially increases linearly with the SHS face displacement until it reaches a magnitude where no or minimal increase occurs with the displacement increase. Subsequently, the force then climbs again with the increase of displacement at lower rate until the test ends.

For analysis purposes, the normalised force-displacement curves of selected samples representing these values i.e. b200t8g60C40-2, b200t8g80C40-4 and b200t8g100C40-1 are plotted in Fig.5. Zoom-in showing the initial part of the force-displacement curves of the same samples is plotted in Fig. 6. The figures show that the bolts gauge variation does not have any effect on the general behaviour as the same pattern was observed in all experiments. The behaviour could be classed into three parts: the initial stiffness part where the force increases sharply with displacement, the yield force part where there is no increase in the force magnitude with the increase of the displacement and lastly the post-yield part where the force undergoes a softer increase with the displacement.

Fig. 5 show that the bolts gauge has a significant effect on the magnitude of the yield force. An increase of about $15 \%$ of the yield force was observed when the bolt gauge increased from $60 \mathrm{~mm}$ to $80 \mathrm{~mm}$. Moreover, when the bolt gauge increased from $80 \mathrm{~mm}$ to $100 \mathrm{~mm}$, the yield force increased by more than $25 \%$. 
The increase of the yield force lay well with the theoretical yield line analysis done in [10]. This is because SHS with wider bolts gauge require more work to bend the SHS face i.e. it provide more resistance, hence higher yield force.

Furthermore, as it can be seen in Fig. 6, the increase of the bolt gauge led to an increase of the initial stiffness of the force-displacement curve representing the SHS face bending behaviour. The post yield part of the curve was almost not affected by the change of bolt gauge in the three tests.

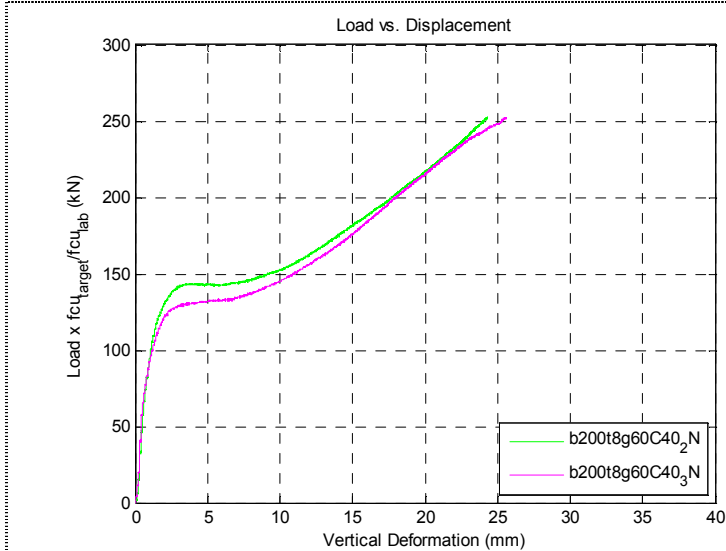

(a) SHS $200 \times 200 \times 8, C 40, g=60 \mathrm{~mm}$

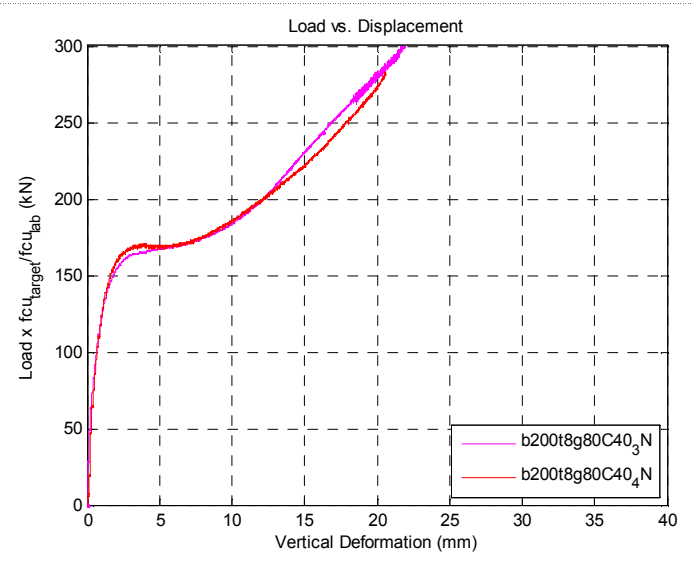

(b) SHS $200 \times 200 \times 8, C 40, g=80 \mathrm{~mm}$

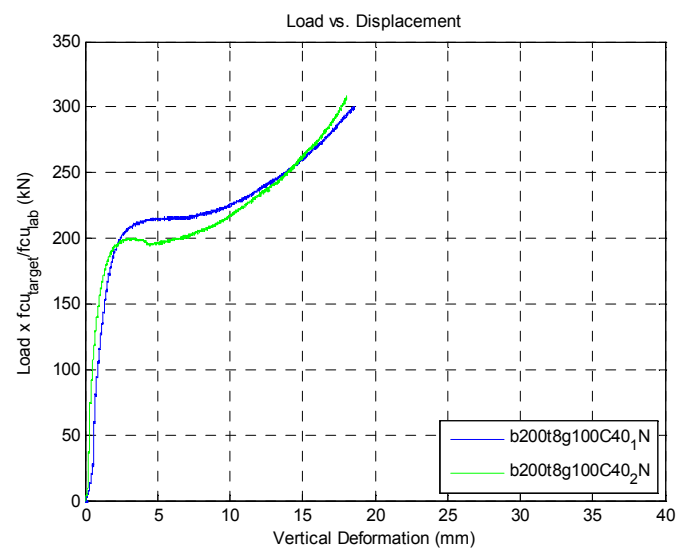

(c) SHS $200 \times 200 \times 8, C 40, \mathrm{~g}=100 \mathrm{~mm}$

Fig. 4: Normalised Force-Displacement relationships

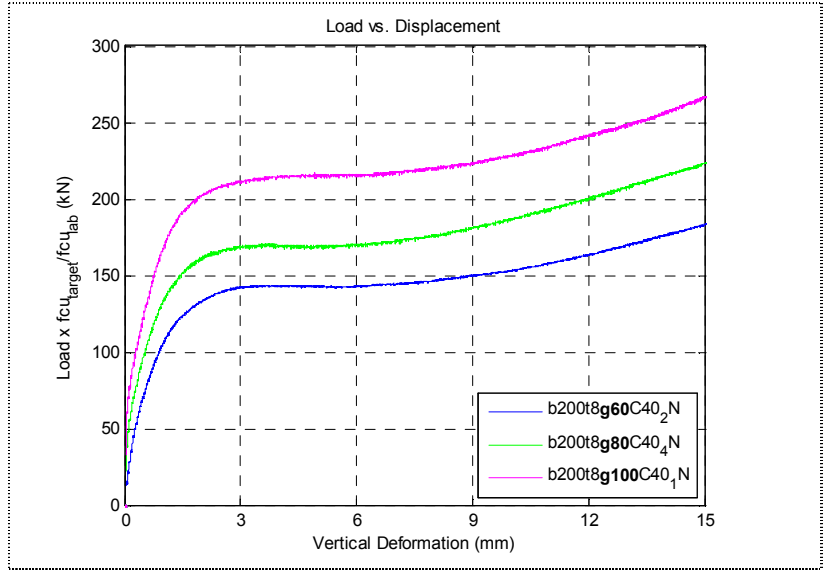

Fig. 5: The effect of bolt gauge on SHS face bending

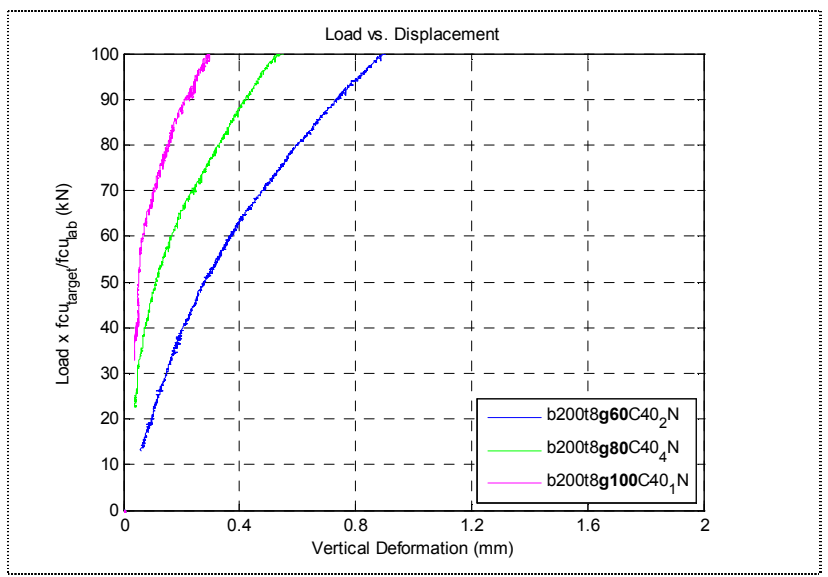

Fig. 6: The effect of bolt gauge on SHS face bending (zoom-in)

Table 2: Concrete-infill data

\begin{tabular}{cccc} 
& \multirow{2}{*}{ Sample ID } & $\mathbf{f}_{\text {cu-target }}$ & $\mathbf{f}_{\text {cu-actual }}$ \\
\cline { 3 - 4 } & & {$\left[\mathbf{N} / \mathbf{m m}^{2}\right]$} & {$\left[\mathbf{N} / \mathbf{m m}^{2}\right]$} \\
\hline 1 & b200t8g60c40-2 & 40 & 40.7 \\
\hline 2 & b200t8g60c40-3 & 40 & 40.7 \\
\hline 3 & b200t8g80c40-3 & 40 & 39.1 \\
\hline 4 & b200t8g80c40-4 & 40 & 39.1 \\
\hline 5 & b200t8g100c40-1 & 40 & 40.8 \\
\hline 6 & b200t8g100c40-2 & 40 & 40.8 \\
\hline
\end{tabular}




\section{Conclusion}

This study shows that varying the bolt gauge affects the face bending behaviour of concrete-filled SHS of Hollo-Bolted connections. For the SHS dimensions tested in this investigation, it was found that the bolt gauge had a significant effect on the magnitude of the yield force. An increase of about $15 \%$ of the yield force was observed when the bolt gauge increased from $60 \mathrm{~mm}$ to $80 \mathrm{~mm}$. Moreover, when the bolt gauge increased from $80 \mathrm{~mm}$ to $100 \mathrm{~mm}$, the yield force increased by more than $25 \%$. The initial stiffness was found to increase with the increase of the bolt gauge. The PostYield stiffness was not affected by the variation of bolt gauge. More work is needed - possibly using finite element modelling - to expand these conclusions to a wider range of SHS geometry and bolt gauge dimensions.

\section{Acknowledgments}

The authors wish to acknowledge TATA Steel (formally Corus) and Lindapter International ${ }^{\circledR}$ for supporting work. Gratitude is expressed to Mr Trevor Mustard, of TATA Steel, and Mr Neil Gill, of Lindapter International.

\section{References}

[1] Lindapter Catalogue: Technical Innovation in Steelwork Connections. Lindapter (2014) (Information on http://www.lindapter.com).

[2] W. Tizani and D. J Ridley-Ellis, The Performance of a new blind-bolt for moment-resisting connections, in: M. A. Jauritta, A. Alonso, and J.A. Chica (Eds.) Tubular Structures X (2003) Madrid, Spain. 395-400.

[3] Eurocode 3: Design of steel structures - Part 1-8: Design of joints. BS EN 1993-1-8:2005. Brussels: CEN (2005).

[4] L. Simões da Silva, A. Santiago and P. Vila Real, A component model for the behaviour of steel joints at elevated temperatures. Journal of Constructional Steel Research (2001), 57, 1169-1195.

[5] E. Bayo, J. M. Cabrero and B. Gil, An effective component-based method to model semi-rigid connections for the global analysis of steel and composite structures. Engineering Structures (2006), 28, 97-108.

[6] C. Málaga-Chuquitaype and A. Y. Elghazouli, Component-based mechanical models for blind-bolted angle connections. Engineering Structures (2010), 32, 3048-3067.

[7] Y. Liu, C. Málaga-Chuquitaype and A. Y. Elghazouli, Response and component characterisation of semi-rigid connections to tubular columns under axial loads. Engineering Structures (2012), 41, 510-532.

[8] A. Y. Park and Y. C Wang, Development of component stiffness equations for bolted connections to RHS columns. Journal of Constructional Steel Research (2012), 70, 137-152.

[9] T. Pitrakkos and W. Tizani, Experimental behaviour of a novel anchored blind-bolt in tension. Engineering Structures (2013), 49, 905-919.

[10] A. Elamin, The Face Bending Behaviour of Blind-Bolted Connections to Concrete-Filled Hollow Sections. PhD, The University of Nottingham (2013).

[11] A. Elamin. The Face Bending Behaviour of Concrete Filled Rectangular Hollow Sections. $\mathrm{PhD} 1^{\text {st }}$ year progress report. The University of Nottingham (2010). 